\title{
Evaluation of Spinodal Pressure for Silicon and Germanium Using Modified Birch-Murnghan and Bardeen Equation of State
}

\author{
Adnan M. Al-Sheikh \\ Department of Physics \\ College of Science \\ University of Mosul \\ E-mail: adnan_alshek
}

\author{
Mumtaz M. Hussien \\ Department of Physics \\ College of Education \\ University of Mosul \\ E-mail: momtaz_hussien
}

\author{
Seham J. Abdullah \\ Department of Physics \\ College of Science \\ University of Mosul \\ E-mail: suham.jasem
}

(Received 18/9/2012; Accepted 17/12/2012)

\begin{abstract}
A modification for Brich-Murnghan EOS and Bardeen EOS to meet the spinodal conditions has been established. Evaluation of spinodal pressure for $\mathrm{Si}$ and $\mathrm{Ge}$, using these modified EOSs show a good agreement with the theoretical results shown in literatures.

Keywords: Spinodal pressure, EOS, negative pressur.

\section{هسلب ضطط السبينودل للسليكهن والجرمانبوم بلستخدالمعادلت الحالة لبرخ عمرنكهل و

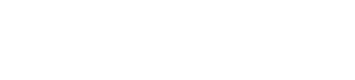

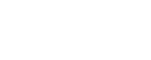

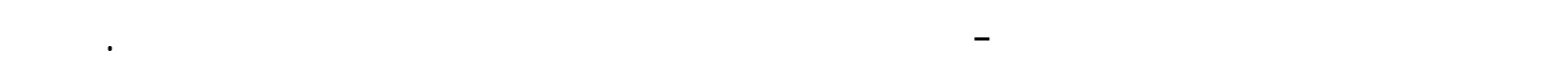
لستخدلم هاتين المعادلتن المحورتين لهسلب ضغط للسبينودال للك من السليكون والجرمانيوم. وأظطهرت المعادلتان المحورتلان نتائج متوافة مع نتائج الأبحلث الظين الظرية. الكاملت الدالة: ضغط للسبينودال، معادلات الحالة، الضغط اللسالب.

\section{INTRODUCTION}

As materials at negative temperature had been studied in liquid nitrogen and liquid helium. The state of materials at negative pressure is metastable and therefore mistakenly thrown out from calculations and neglected in experiments as non-existing or unaccessible ones although they exist since the beginning of the universe and, they have been studied since Huygens (Attila, 2007). An equation of state expressing relationship between pressure, volume and temperature that helps to understand the behavior of materials under the effect of high pressure and high temperature. Up to now, a number of workers (Singh and Singh, 2012), (Singh, 2011), and (Zhen et al., 2010) have endeavored to search for a simple form of the equation of state (EOS), which has a small number of parameters. The parameters are determined by using available low-pressure data such as the equilibrium volume $\left(\mathrm{V}_{\mathrm{o}}\right)$, the isothermal bulk modulus $\left(\mathrm{B}_{\mathrm{o}}\right)$ and its pressure derivatives $\left(\mathrm{B}_{\mathrm{o}}^{\prime}\right)$ and $\left(\mathrm{B}_{\mathrm{o}}{ }_{\mathrm{o}}\right)$ at atmospheric
\end{abstract}


pressure. Although the Vinet equation of state (EOS) as illustrated below (Vinet et al.,1986):

$$
p_{v}=3 B_{o}\left(\frac{V}{V_{o}}\right)^{-2 / 3}\left(1-\left(\frac{V}{V_{o}}\right)^{1 / 3}\right) \exp \left[\left\{\frac{3}{2}\left(B_{o}^{\prime}-1\right)\right\}\left(1-\left(\frac{V}{V_{o}}\right)^{1 / 3}\right)\right]
$$

Where: P: pressure, and subscript $v$ refer to Vinet EOS. V: volume at pressure (p). $\mathrm{V}_{\mathrm{o}}$ : volume at atmospheric pressure. $\mathrm{B}_{0}$ : the bulk modulus at atmospheric pressure.

Has been considered as a universal equation of state (EOS), it cannot meet the requirements to be an ideal equation of state (EOS). An ideal universal EOS should have the following four merit: First: the energy should be analytic, $U=U(V)$. Second: the EOS should be both pressure analytic, $\mathrm{P}=\mathrm{P}(\mathrm{V})$ and volume analytic, $\mathrm{V}=\mathrm{V}(\mathrm{P})$. Third: it should satisfy the following spinodal condition (Jiuxun, 2005).

$$
B \alpha\left(p-p_{s p}\right)^{1 / 2}, \text { with } \quad B \alpha\left(P-P_{s p}\right)=0
$$

Where: $P_{s p}$ : spinodal pressure. $B$ : the bulk modulus.

and have the correct limit as volume tends to infinity, $\mathrm{P}(\mathrm{V} \rightarrow \infty)=0$, and be applicable to expanded materials, including expanded liquids and solids. Fourth: it should have a high enough precision with a simple form and a small number of parameters, and allow one to predict the compression curve for materials at a high pressure using only the parameters determined from the experimental data at low pressure. The equation of state (EOS) corresponding to the generalized Lennard Jones (GLJ) potential (U), does not meet the ideal EOS requirements, as the exponents contained in the potential function take arbitrary values.

$$
U=\frac{B_{o} V_{o}}{n}\left(\frac{V_{o}}{V}\right)^{n-1}\left[(2 n-1)^{-1}\left(\frac{V_{o}}{V}\right)^{n}-(n-1)^{-1}\right]
$$

Jiuxun (2005) making the exponents satisfy the following relationship.

$$
p=\frac{B_{o}}{n}\left(\frac{V_{o}}{V}\right)^{n}\left[\left(\frac{V_{o}}{V}\right)^{n}-1\right]
$$

Where:

$$
n=\frac{1}{3} B_{o}^{\prime}
$$

Since $\mathrm{B}_{\mathrm{T}}$ is expressed as

$$
B_{T}=-V \frac{\partial p}{\partial V}
$$


Then

$$
B_{T(M L J)}=B_{o}\left(\frac{V_{o}}{V}\right)^{n}\left[2\left(\frac{V_{o}}{V}\right)^{n}-1\right]
$$

with

$$
\left(\frac{V_{o}}{V_{s p}}\right)^{n}=\frac{1}{2} \quad \text { and } \quad p_{s p}=-\frac{B_{o}}{4 n}
$$

In the present work, a modification for B-M EOS and Bardeen EOS has been established to meet the spinodal condition, and the evaluation of spinodal pressure for silicon and germanium has been achieved.

\section{THEORETICAL DETAILS}

\section{The Spinodal Pressure}

The spinodal pressure for a material is defined as the negative pressure at which the bulk modulus of the material goes to zero. Using Birch- Murnghan $\left(\mathrm{P}_{\mathrm{BM}}\right),(\mathrm{Birch}, 1952)$ and Bardeen $\left(\mathrm{P}_{\mathrm{B}}\right)$, (Bardeen, 1938) EOS.

$$
\begin{aligned}
& P_{B M}=\frac{3 B_{o}}{2}\left[\left(\frac{V}{V_{o}}\right)^{-7 / 3}-\left(\frac{V}{V_{o}}\right)^{-5 / 3}\right]\left[1+\frac{3}{4}\left(B_{o}^{\prime}-4\right)\left(\left(\frac{V}{V_{o}}\right)^{-2 / 3}-1\right)\right] \\
& P_{B}=3 B_{o}\left[\left(\frac{V}{V_{o}}\right)^{-5 / 3}-\left(\frac{V}{V_{o}}\right)^{-4 / 3}\right]\left[1+\frac{3}{2}\left(B_{o}^{\prime}-3\right)\left(\left(\frac{V}{V_{o}}\right)^{-1 / 3}-1\right)\right]
\end{aligned}
$$

Then by combining eq. 6 with eq. 9 one time, and eq. 6 with eq.10 another time one obtains:

$$
\begin{aligned}
& B_{T(B M)}=\frac{B_{o}}{2}\left[\frac{27}{4}\left(B_{o}^{\prime}-4\right)\left(\frac{V}{V_{o}}\right)^{-3}+\left(7-\frac{42}{4}\left(B_{o}^{\prime}-4\right)\right)\left(\frac{V}{V_{o}}\right)^{-7 / 3}\right. \\
& \left.+5\left(\frac{3}{4}\left(B_{o}^{\prime}-4\right)-1\right)\left(\frac{V}{V_{o}}\right)^{-5 / 3}\right] \\
& B_{T(B)}=B_{o}\left[9\left(B_{o}^{\prime}-3\right)\left(\frac{V}{V_{o}}\right)^{-2}-5\left(3\left(B_{o}^{\prime}-3\right)-1\right)\left(\frac{V}{V_{o}}\right)^{-5 / 3}\right. \\
& \left.-4\left(1-\frac{3}{2}\left(B_{o}^{\prime}-3\right)\right)\left(\frac{V}{V_{o}}\right)^{-4 / 3}\right]
\end{aligned}
$$

An approach for evaluating spinodal pressure has been established, by modifying eq.11 and eq.12, to meet the spinodal condition. 


\section{CALCULATION AND RESULT}

On introducing the spinodal condition, where $\mathrm{B}_{\mathrm{T}(\mathrm{BM})}=0$, in eq. 11 and $\mathrm{B}_{\mathrm{T}(\mathrm{B})}=0$ in eq. 12 . We obtain $\left(\frac{V_{s p}}{V_{o}}\right)$ for Si and Ge by using eq.11 as:

$\left(\frac{V_{s p}}{V_{o}}\right)_{B M(S i)}=1.6197 \quad,\left(\frac{V_{s p}}{V_{o}}\right)_{B M(G e)}=1.5718$

While on putting $\mathrm{B}_{\mathrm{T}(\mathrm{B})}=0$ in eq. 12 we obtain $\left(\mathrm{V}_{\mathrm{sp}} / \mathrm{V}_{\mathrm{o}}\right)$ for $\mathrm{Si}$ and Ge as $\left(\frac{V_{s p}}{V_{o}}\right)_{B(S i)}=1.5702, \quad\left(\frac{V_{s p}}{V_{o}}\right)_{B(G e)}=1.5025$

By using the values of $\left(\mathrm{B}_{0}, \mathrm{~B}_{\mathrm{o}}^{\prime}\right)$ listed in Table (1) for $\mathrm{Si}$ and $\mathrm{Ge}$ and substituting eq.13 for eq. 9, we obtain $\left(\mathrm{P}_{\mathrm{sp}}\right)_{\mathrm{BM}}$ for $\mathrm{Si}$ and $\mathrm{Ge}$ as shown in Table (2). Similarly, by substituting eq.14 for eq.10, we obtain $\left(\mathrm{P}_{\mathrm{sp}}\right)_{\mathrm{B}}$ for $\mathrm{Si}$ and Ge. Table (2).

Table 1: The experimental values of bulk modulus $B_{0}$, and its first pressure derivative $B_{0}^{\prime}$ for Si and Ge (Tripathi et al., 2006).

\begin{tabular}{|c|c|c|}
\hline Material & $\mathbf{B}_{\mathbf{0}}(\mathbf{G p a})$ & $\mathbf{B}_{\mathbf{0}}^{\prime}$ \\
\hline $\mathrm{Si}$ & 98.0 & 4.24 \\
\hline $\mathrm{Ge}$ & 77.2 & 4.55 \\
\hline
\end{tabular}

Table 2: Values of spinodal pressure $\left(\mathbf{P}_{\mathrm{sp}}\right)$ and $\left(V_{s p} / V_{o}\right)$ for $\mathrm{Si}$ and Ge by using modified EOS

\begin{tabular}{|c|c|c|c|c|c|c|}
\hline \multirow{3}{*}{ Material } & \multicolumn{4}{|c|}{ Present work } & \multicolumn{2}{c|}{ Jiuxun, 2005 } \\
\cline { 2 - 6 } & \multicolumn{2}{|c|}{ M. Birch- Murnghan EOS } & \multicolumn{2}{c|}{ M. Bardeen EOS } & \multicolumn{2}{c|}{} \\
\cline { 2 - 7 } & $\frac{V_{s p}}{V_{o}}$ & $P_{s p}$ & $\frac{V_{s p}}{V_{o}}$ & $P_{s p}$ & $\frac{V_{s p}}{V_{o}}$ & $P_{s p}$ \\
\hline $\mathrm{Si}$ & 1.6197 & -17.1968 & 1.5702 & -16.6521 & 1.6329 & -17.3349 \\
\hline $\mathrm{Ge}$ & 1.5718 & -12.6617 & 1.5025 & -12.0398 & 1.5793 & -12.7253 \\
\hline
\end{tabular}




\section{DISCUSSION}

The results obtained from the present work, tabulated in Table (2), show that the modification of B-M EOS and Bardeen EOS to meet the spinodal condition can be achieved on the basis of spinodal pressure definition $\left(B_{T}=0\right)$. The present results Table (2) show a complete agreement with other works (Jiuxun, 2005). On the other hand, as referred in the introduction, applying the same approach to Vinet EOS, shows that Vinet EOS can not meet the spinodal condition although it is known as a universal EOS. The negative pressure study is a promising approach to achieve an ideal universal EOS.

\section{REFERENCES}

Attila, R. Imer (2007). On the existence of negative pressure states. Physica Status Solidi (b)., 244, 893-899.

Bardeen, J. J. (1938). Compressibility's of the alkali metals. Chem. Phys., 6, 372.

Birch, F. (1952). Elasticity and constitution of the earth's interior. Geophys. Res., 57, 227.

Jiuxun, S. (2005). A modified Lennard-Jones-type equation of state for solids strictly satisfying the spinodal condition. J. Phys. Condens. Matter, 17, L103-L111.

Singh, P. K. (2011). Pressure dependence of bulk modulus for solids based on the firstprinciples results. Indian J. Pure and Appl. Phys., 49, 829-832.

Singh, S.P.; Singh, J. (2012). Thermal expansively and isothermal bulk modulus of various classes of minerals at high temperature. J. Pure and Appl. Sci. and Tech., 2(2), 5463.

Tripathi, P.; Misra, G.; Goyal, S.C. (2006). Equation of state for group IV-IV semiconductors. Solid State Communications, 139,132-137.

Vinet, P.; Ferraute, J.; Smith, J. R.; Rose, J. (1986). A universal equation of state for solids. J. Phys. C:Solid 19, L 467-L 473.

Zhen-Hua Wang; Xiao-Yu Kuang; Xiao-Fen Huang; Peng Lu; AI-Jie Mao. (2010). Pressure-induced structureal transition and thermodynamic properties of $\mathrm{NbN}$ and effect of metallic bonding on its hardness. A letters J. Exploring (EPL), 92, 56002. 